\title{
The Effect of Confluence Angle on the Flow Pattern at a Rectangular Open-Channel
}

\author{
Firooz Rooniyan \\ Department of Civil Engineering \\ Islamic Azad University, Ahar Branch \\ Ahar, Iran \\ pirooz.rounia@gmail.com
}

\begin{abstract}
Flow connection in channels is a phenomenon which frequently happens in rivers, water and drainage channels and urban sewage systems. The phenomenon appears to be more complex in rivers than in channels, especially at the y-junction bed joint that causes erosion and sedimentation at some areas resulting to morphological changes. Flow behavior at the channel junction area depends on variables such as channel geometry, discharge ratio, tributary width and y-junction connection angle of the channel, bed level changes at the bed joint, flow characteristic at the bed joint upstream and flow Froude number in different sections. In this research, fluent numerical model and junction angles of $30^{\circ}, 45^{\circ} \& 60^{\circ}$ are used to analyze and evaluate the effect of channel junction geometry on the flow pattern and the flow separation zone dimensions in different ratios of flow discharge (upstream channel discharge to total discharge of the flow). Results for two ratios of flow discharge are represented. Results are in agreement with earlier studies and it is shown that the change of the channel crossing angle affects the flow pattern in the main channel and also that the dimensions of the created separation zone in the main channel become larger when the crossing angle increases. This phenomenon can also be observed when the flow discharge ratio is lower. Analysis showed that the least dimension of the separation zone will be at the crossing angle of $45^{\circ}$.
\end{abstract}

Keywords- flow pattern; transverse channel; y-junction; rectangular channel; fluent Numerical Model

\section{INTRODUCTION}

One of the flows which leaves important effects on river and channels bed i.e. erosion, scour and sedimentation is the so called transverse flow, which in fact is formed as the result of the collision of two flows with similar or different characteristic. Various parameters affect the flow pattern in transverse channels and thus analysis may be difficult. These parameters include geometric parameters (channel form, channel dimensions, angle between main and tributary channel) and hydraulic parameters (Froude number of flow, discharge ratio in main and tributary channel). Taylor [1] was the first to analyze flow issues in transverse channels. By analyzing momentum equation he represented an equation to obtain flow depth ratio in upstream and downstream channels. Hsu at el. [2] represented an equation to obtain flow depth ratio by solving of energy and momentum equations. They also analyzed transverse channels with the angles of $30^{\circ}, 45^{\circ} \& 60^{\circ}$. Weber et al. [3] tested flow patterns at $90^{\circ}$ transverse channels. The data evaluated by Weber and his colleagues were in the form of three dimensional speeds along with speed and flow depth variations. These data provided an equivalent bed for validity measurement of mathematical models. Ramamurthy et al. [4] studied flow characteristics at the confluence of a rectangular open channel of $90^{\circ}$ including equal width and they also analyzed the flow pattern at the confluence of channels by using three dimensional turbulence models and evaluated their results by using lab data. Lab data confirmed the accuracy of their three dimensional turbulence model. Nania et al. [5] perform a lab study on subcritical flows at the four-way intersection with equal width and two inflows and two outflows. Results indicated that there is a linear relation between five dimensionless parameters which include the inflow ratio, the outflow ratio, the inflow Froude number in one direction and the outflow depth ratio. They also represented an acceptable prognosis about flow distribution at a channel junction. Ghobadian [6] analyzed the effect of downstream water level changes on the secondary flow pattern at the confluence of a rectangular open channel and showed that it is possible to simulate the transverse flow by using a three dimensional model. Qohari [7] analyzed the flow pattern at the $90^{\circ}$ junction by using Fluent and lab models and resulted that the Fluent numerical model had the capability to simulate the flow dynamic at channels junction and also that the simulation of the secondary flow at the junction of $90^{\circ}$ was satisfying and that there was a correlation between the results.

\section{MATERIALS AND METHODS}

In this article, the effect of two important parameters is analyzed. Simulation for all represented flow ratios is shown in Table I and for cross sections of $\mathrm{X}^{*}=5.5$ to $\mathrm{X}^{*}=8.38$ are shown in Figure 1. Three junction angles of 30, 45 and 60 were employed for the two parameters i.e. channel junction angle and flow discharge ratio. Lines of longitudinal and latitudinal flow near the bed and flow level were done only for two discharge ratios of $Q^{*}=0.083$ and $Q^{*}=0.917$. Nowadays, developing and applying three dimensional mathematical models at river engineering is very popular although the 
accuracy of developed models has always to be confirmed. However, considering the expenses related to lab instruments and the limitations of measuring machines, it is easy to understand why the application of numerical models has increasing in hydrology. The Fluent 6.3 .26 software is used in this article.

TABLE I. LAB DATA SPECIFICATIONS FOR FLOW AT JUNCTIONS

\begin{tabular}{|c|c|c|c|c|c|c|}
\hline $\mathbf{Q}_{\mathbf{m}}\left(\mathbf{m}^{3} / \mathbf{s e c}\right)$ & 0.014 & 0.042 & 0.071 & 0.099 & 0.127 & 0.156 \\
\hline $\mathbf{Q}_{\mathbf{b}}\left(\mathbf{m}^{3} / \mathbf{s e c}\right)$ & 0.156 & 0.127 & 0.099 & 0.071 & 0.042 & 0.014 \\
\hline $\left.\mathbf{Q}^{*}=\mathbf{Q}_{\mathbf{m}} / \mathbf{Q}_{\mathbf{m}}+\mathbf{Q}_{\mathbf{b}}\right)$ & 0.083 & 0.25 & 0.417 & 0.583 & 0.75 & 0.917 \\
\hline
\end{tabular}

\section{GOVERNING EQUATIONS}

Governing equations on motion of viscous incompressible fluid in the condition of turbulence are expressed by NavierStokes equations. The cohesion equation (conservation of mass) and the momentum equation (conservation of momentum) are:

$$
\frac{\partial u_{i}}{\partial x_{i}}=0
$$

and

$$
\frac{\partial u_{i}}{\partial t}+\frac{\partial u_{i} u_{j}}{\partial x_{i}}=-\frac{1}{\rho} \frac{\partial P}{\partial x_{i}}+g_{i}+\frac{\partial}{\partial x_{i}}\left(\tau_{i j}\right)
$$

In which, $u_{i}$ denotes the velocity component in the direction of $x_{i}, \mathrm{P}$ is the total pressure, $\rho$ is the fluid's density, $g_{i}$ is the gravity acceleration in the direction of $x_{i}$ and $\tau_{i j}$ is the stress tensor responsible of the effect of the turbulence eddy.

Fluent is a two or three dimensional analysis software of flow which is able to model fluid flow and heat transfer in complex geometries by using cohesion equations and NavierStokes. This software is written in $\mathrm{C}$ and uses the constrained volume method. All flow analyses are performed in the steady condition and the SIMPLE algorithm is used to couple velocity and pressure.

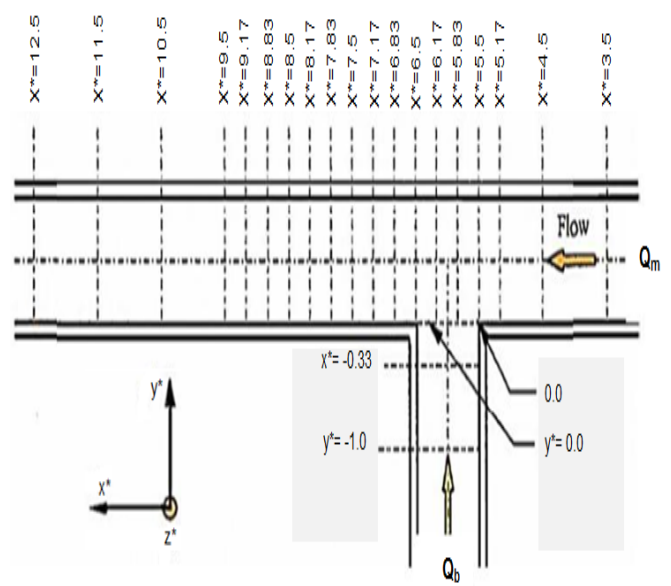

Fig. 1. Different flow velocity measurement at channel.
The breaching method of momentum equations, the loss of turbulent kinematical energy and Reynolds stresses have been selected as two order modern methods and the breaching method of pressure equation is selected as a standard method. Also $\mathrm{k}-\omega$ is selected as a turbulent method and the equivalent grillage is considered in the area under viscous area and near the wall. Field geometry is provided using Gambit 2.3.16 software. The distance of the first node at the under-viscous area is considered $1 \mathrm{~mm}$ and gradually by going far from the bank, the distance of the nodes becomes larger and the become coarser.

\section{RESULTS}

\section{A. Flow Longitudinal Velocity Lines}

Flow velocity lines at the xy plate for the three junction angles (i.e. $30,45,60)$ and for flow near the level $\left(z^{*}=0.278\right)$ and near the bed $\left(z^{*}=0.014\right)$ is depicted in Figures 2 to 7 . These diagrams have been drawn for the maximum discharge ratio of flow $\left(Q^{*}=0.197\right)$ and the minimum discharge ratio of flow $\left(Q^{*}=0.083\right)$ as shown in Table I. It was observed that the combination of main and tributary channel flow resulted in the formation of a secondary flow which is affected by the flow discharge ratio and the junction angle. This secondary flow is completely three-dimensional and turbulent. This issue can be mostly observed in the junction of $45^{\circ}$ and $60^{\circ}$ and for a discharge ratio of $\mathrm{Q}^{*}=0.083$ (Figures 4 and 6 ).

Velocity lines for different junction angles get closer to the left bank near the level and closer to right bank near the bed. This issue occurs due to the flow momentum difference at the level in comparison with the bed, and this causes the flow separation zone dimensions at the level to become larger compared to the ones at the bed. Tables IV and V verify this claim. The separation zone is observed in all simulations and for other flow discharge ratios.

In case of a discharge ratio of $\mathrm{Q}^{*}=0.917$ (high main channel discharge), a turbulence mostly extend into the tributary channel which causes the formation of a separation zone in the left bank of the tributary channel (Figure 9), and decrease the dimensions of the separation zone at the main channel. This occurs because of the high momentum of the main channel.

\section{B. Parametric Study of Junction Angle Effect on Flow Profile}

In this section, a parametric study of flow junction angle effect analyses is performed on the separation zone dimensions at the main channel downstream. Therefore, three junction angles of $30^{\circ}, 45^{\circ} \& 60^{\circ}$ have been evaluated. All six ratios of flow regarding the model and the effect of the junction angle on the separation zone dimensions have been analyzed for each angle. Model outlets show that the separation zone occurs in all discharge ratios for all three junction angles. Also that it reaches its minimum value at the junction of $45^{\circ}$ and in both ratios of flow at the bed and level. 

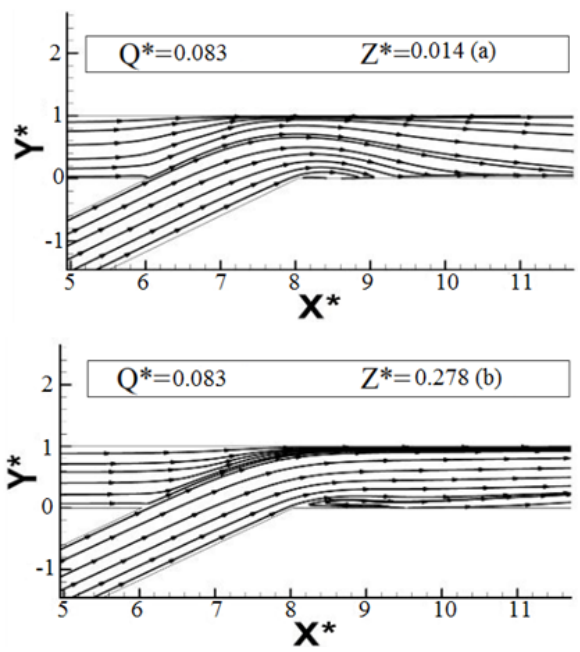

Fig. 2. Streamlines at $30^{\circ}$ junction for $\mathrm{Q}^{*}=0.083$ near water surface and flow bottom.
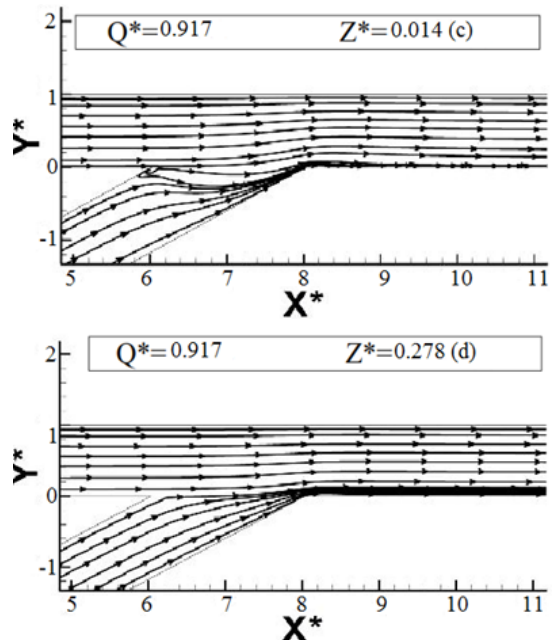

Fig. 3. Streamlines at $30^{\circ}$ junction for $\mathrm{Q}^{*}=0.917$ near water surface and flow bottom.
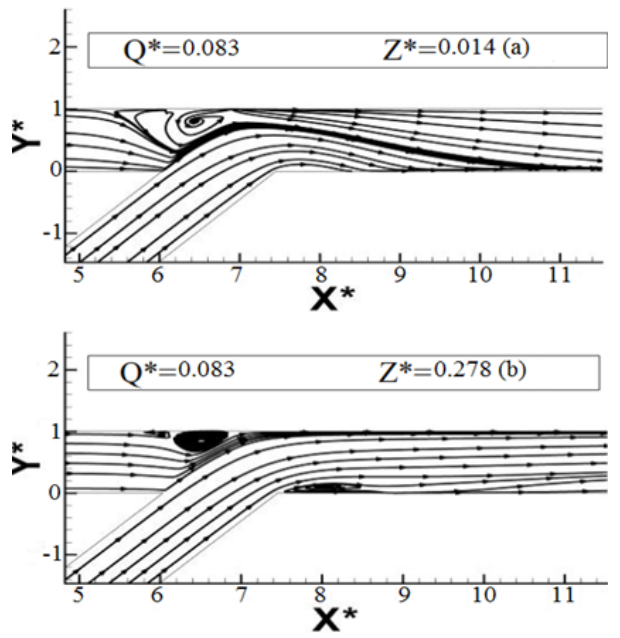

Fig. 4. Streamlines at $45^{\circ}$ junction for $\mathrm{Q}^{*}=0.083$ near water surface and flow bottom.
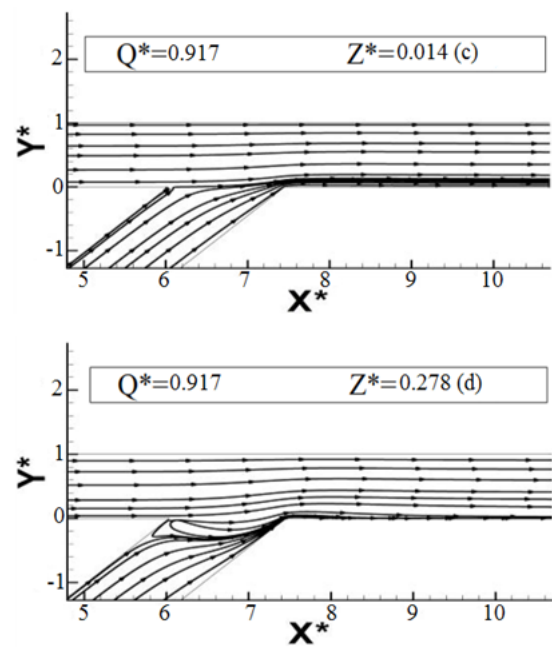

Fig. 5. Streamlines at $45^{\circ}$ junction for $\mathrm{Q}^{*}=0.917$ near water surface and flow bottom.
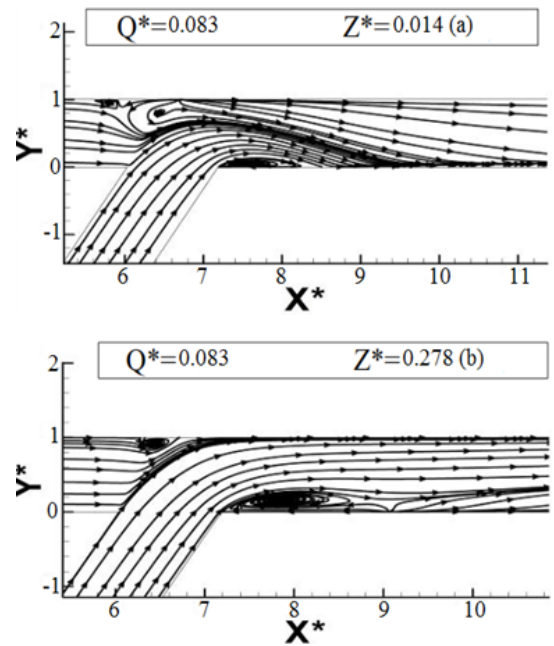

Fig. 6. Streamlines at $60^{\circ}$ junction for $\mathrm{Q}^{*}=0.083$ near water surface and flow bottom.
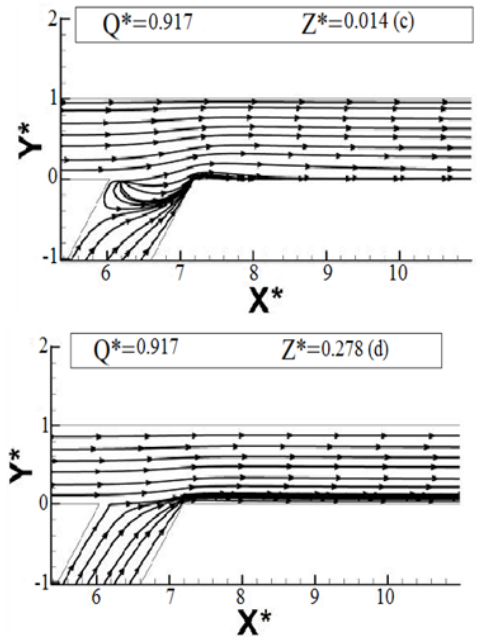

Fig. 7. Streamlines at $60^{\circ}$ junction for $\mathrm{Q}^{*}=0.917$ near water surface and flow bottom. 
This phenomenon can be observed by in the represented values in Tables IV and V for the dimensions of the created rotational zone in the main channel. In this table, the separation zone length and width at the channel of $45^{\circ}$ for the flow ratio $\mathrm{Q}^{*}=0.083$ is equal to 0.09 and 0.012 at the bed, and at the level is equal to 1.3 and 0.1 and for the flow ratio of $Q^{*}=0.917$ it is equal to 0.007 and 0.003 at the bed and equal to 0.14 and 0.005 at the level. By comparing these values with other values in Tables IV and V the following can be noticed:

- The separation zone at the junction of $45^{\circ}$ is smaller than the other angles.

- The flow separation zone of this junction angle is small.

Also, by increasing the flow ratio from 0.083 to 0.917 the separations zone dimensions become smaller. By referring to Figures 4 and 6 , it can be noticed that at a flow ratio of $\mathrm{Q}=0.083$ and for junction angles of $45^{\circ}$ and $60^{\circ}$, a turbulent zone is formed at the left of the main channel with longitudinal velocity vectors being in this area. Analysis indicates that the dimensions of turbulence at $45^{\circ}$ junction have a decreasing trend in comparison to the $60^{\circ}$ junction and that at any of these junctions' turbulent zone dimensions decrease from bed to level (Figure 8). Dimensions of turbulence for two angles which verifies this fact is represented in table (2).

TABLE II. DIMENSIONS OF TURBULENT IN MAIN CHANNEL

\begin{tabular}{|c|c|c|c|c|c|}
\hline No. & $\mathrm{Q}^{*}=\mathrm{Q}_{\mathrm{m}} /\left(\mathrm{Q}_{\mathrm{m}}+\mathrm{Q}_{\mathrm{b}}\right)$ & $\begin{array}{c}\text { Junction } \\
\text { angle } \\
\text { bottom }\left(\mathrm{Z}^{*}\right)\end{array}$ & $\begin{array}{c}\text { Distance } \\
\text { to channel } \\
\left(\mathrm{L}^{*}\right)\end{array}$ & $\begin{array}{c}\text { Zone } \\
\text { length } \\
\left(\mathrm{D}^{*}\right)\end{array}$ & $\begin{array}{c}\text { Zone } \\
\text { width }\end{array}$ \\
\hline 1 & 0.083 & 60 & 0.014 & 1.1 & 0.29 \\
\hline 2 & 0.083 & 60 & 0.278 & 0.48 & 0.08 \\
\hline 3 & 0.083 & 60 & 0.014 & 1.7 & 0.32 \\
\hline 4 & 0.083 & 60 & 0.278 & 1.6 & 0.15 \\
\hline
\end{tabular}

In addition outlets indicate a separation zone inside the tributary channel near the left bank at the junction of $45^{\circ}$ and $60^{\circ}$ for flow ratio of $\mathrm{Q}^{*}=0.917$ which this zone was not observed in $30^{\circ}$ angle.

This is because of high flow discharge in main channel which causes some part of created turbulent in main channel extend into tributary channel and from turbulent zone in tributary channel. By comparing table (3) values that indicate dimensions of turbulent zone in tributary channel, it can be resulted that dimensions of this zone at the junction of $45^{\circ}$ than the junction of $60^{\circ}$ has increasing trend regarding length but decreasing trend in the respect of width. Also it was observed that created separation zone dimensions decrease from bed to level for a specified junction angle.

As shown in Figures 2 to 7 , for a specific junction angle increased flow discharge ratio relates to decreased flow separation zone dimensions. Another result is that a change of junction angle and flow ratio will cause the flow separation zone in the main channel to be displaced. A decrease of the junction angle or an increase of the discharge ratio, will cause it to be inclined towards the right bank and at the bed, in comparison to the level, it becomes closer to the right bank.
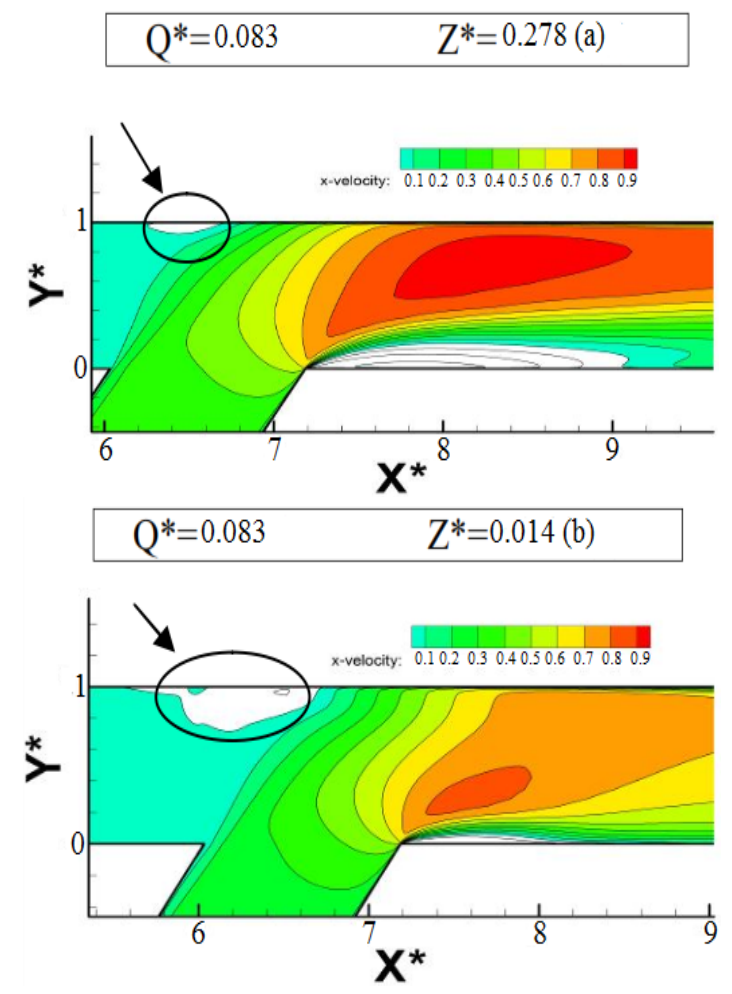

Fig. 8. Separation zone in tributary channel at $60^{\circ}$ junction for $Q^{*}=0.083$ near water surface and flow bottom.
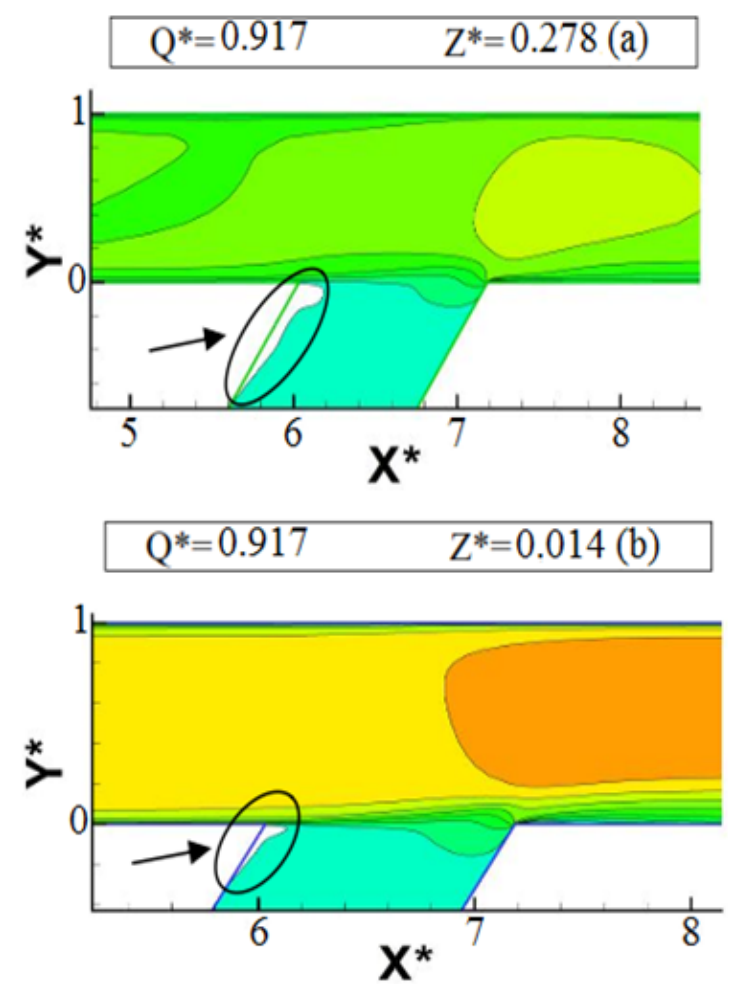

Fig. 9. Separation zone in tributary channel at $60^{\circ}$ junction for $Q^{*}=0.917$ near water surface and flow bottom. 
TABLE III. DIMENSIONS OF THE SEPARATION ZONE IN THE TRIBUTARY CHANNEL

\begin{tabular}{|c|c|c|c|c|c|}
\hline No. & $\mathrm{Q}^{*}=\mathrm{Q}_{\mathrm{m}} /\left(\mathrm{Q}_{\mathrm{m}}+\mathrm{Q}_{\mathrm{b}}\right)$ & $\begin{array}{c}\text { Junction } \\
\text { angle } \\
\text { bottom }\left(\mathrm{Z}^{*}\right)\end{array}$ & $\begin{array}{c}\text { Distance } \\
\text { to channel } \\
\left(\mathrm{L}^{*}\right)\end{array}$ & $\begin{array}{c}\text { Zone } \\
\text { length } \\
\left(\mathrm{D}^{*}\right)\end{array}$ & $\begin{array}{c}\text { Zone } \\
\text { width }\end{array}$ \\
\hline 1 & 0.917 & 60 & 0.014 & 0.7 & 0.2 \\
\hline 2 & 0.917 & 60 & 0.278 & 0.3 & 0.1 \\
\hline 3 & 0.917 & 60 & 0.014 & 1.13 & 0.43 \\
\hline 4 & 0.917 & 60 & 0.278 & 0.07 & 0.13 \\
\hline
\end{tabular}

TABLE IV. DIMENSIONS OF THE ROLLER ZONE FOR Q ${ }^{*}=0.083$ AND $Q^{*}=0.917$ NEAR THE FLOW BOTTOM

\begin{tabular}{|c|c|c|c|c|c|}
\hline No. & $\mathrm{Q}^{*}=\mathrm{Q}_{\mathrm{m}} /\left(\mathrm{Q}_{\mathrm{m}}+\mathrm{Q}_{\mathrm{b}}\right)$ & $\begin{array}{c}\text { Junction } \\
\text { angle } \\
\text { bottom }\left(\mathrm{Z}^{*}\right)\end{array}$ & $\begin{array}{c}\text { Distance } \\
\text { to channel } \\
\left(\mathrm{L}^{*}\right)\end{array}$ & $\begin{array}{c}\text { Zone } \\
\text { length } \\
\left(\mathrm{D}^{*}\right)\end{array}$ & $\begin{array}{c}\text { Zone } \\
\text { width }\end{array}$ \\
\hline 1 & 0.083 & 60 & 0.014 & 1.25 & 0.0625 \\
\hline 2 & 0.917 & 60 & 0.014 & 0.047 & 0.005 \\
\hline 3 & 0.083 & 45 & 0.014 & 0.09 & 0.012 \\
\hline 4 & 0.917 & 45 & 0.014 & 0.007 & 0.003 \\
\hline 5 & 0.083 & 30 & 0.014 & 0.7 & 0.025 \\
\hline 6 & 0.917 & 30 & 0.014 & 0.022 & 0.004 \\
\hline
\end{tabular}

TABLE V. DIMENSIONS OF THE ROLLER ZONE FOR Q*=0.083 AND $Q^{*}=0.917$ NEAR THE WATER SURFACE

\begin{tabular}{|c|c|c|c|c|c|}
\hline No. & $\mathrm{Q}^{*}=\mathrm{Q}_{\mathrm{m}} /\left(\mathrm{Q}_{\mathrm{m}}+\mathrm{Q}_{\mathrm{b}}\right)$ & $\begin{array}{c}\text { Junction } \\
\text { angle } \\
\text { bottom }\left(\mathrm{Z}^{*}\right)\end{array}$ & $\begin{array}{c}\text { Distance } \\
\text { to channel } \\
\left(\mathrm{L}^{*}\right)\end{array}$ & $\begin{array}{c}\text { Zone } \\
\text { length } \\
\left(\mathrm{D}^{*}\right)\end{array}$ & $\begin{array}{c}\text { Zone } \\
\text { width }\end{array}$ \\
\hline 1 & 0.083 & 60 & 0.278 & 1.9 & 0.175 \\
\hline 2 & 0.917 & 60 & 0.278 & 0.3 & 0.013 \\
\hline 3 & 0.083 & 45 & 0.278 & 1.3 & 0.1 \\
\hline 4 & 0.917 & 45 & 0.278 & 0.14 & 0.005 \\
\hline 5 & 0.083 & 30 & 0.278 & 1.45 & 0.1 \\
\hline 6 & 0.917 & 30 & 0.278 & 0.46 & 0.02 \\
\hline
\end{tabular}

\section{CONCLUSION}

In this article, flow profile and flow separation zone dimensions at three junction angles of $30^{\circ}, 45^{\circ}$ and $60^{\circ}$ for flow ratio of $\mathrm{Q}^{*}=0.083$ and $\mathrm{Q}^{*}=0.917$ have been investigated by using a Fluent numerical model. Formation of the flow rotational zone and turbulence are simulated fairly good and the following results are obtained:

- For a discharge ratio of $\mathrm{Q}^{*}=0.917$ in the case that main channel discharge is high, created turbulence will be drawn mostly into the tributary channel and will decrease the separation zone dimensions in the main channel and also cause another separation zone in the tributary channel due to the high momentum of the main channel.

- In a specific junction angle and constant flow ratio, separation zone dimensions increase from bed to level.

- Simulation indicate that flow separation zone occurs at any of the six discharge ratios and for all junction angles and at the junction of $45^{\circ}$ it reaches the minimum value for both flow ratios.

- Flow separation zone dimensions at the downstream of the main channel decrease with the increase of flow discharge ratio for a specific junction angle.
- For a discharge ratio of $\mathrm{Q}^{*}=0.083$ and at the junction angle of $45^{\circ}$ and $60^{\circ}$, a turbulent zone is formed at the left side of the main channel, created by the high momentum of tributary channel. Analysis indicate that turbulence dimensions are larger at the junction of $45^{\circ}$ than at the junction of $60^{\circ}$ and that turbulence dimensions decrease from bed to level at both junctions. Also longitudinal velocity vectors are negative in this area.

- For a specific discharge ratio and with an increase of junction angle, separation zone dimensions increase, a process observable at level and near the bed.

- Obtained results showed that the angle of $45^{\circ}$ has the least effect on the main channel flow compared to the two angles and that this angle can be considered as an optimum angle at channel junctions.

\section{REFERENCES}

[1] E. H. Taylor, "Flow Characteristics at Rectangular Open-Channel Junctions", Transactions of the American Society of Civil Engineers, Vol. 109, pp. 893-902, 1944

[2] C. C. Hsu, F. S. Wu, W. J. Lee, "Flow at $90^{\circ}$ Equal-Width Open-Channel Junction", ASCE Journal of Hydraulic Engineering, Vol. 124, No. 2, pp. 186-191, 1998

[3] L. J. Weber, E. D. Shumate, N. Mawer, "Experiments on Flow at a $90^{\circ}$ Open Channel Junction", ASCE Journal of Hydraulic Engineering, Vol. 127, No. 55, pp. 340-350, 2001

[4] A. S. Ramamurthy, J. Qu, D. Vo, "Numerical and Experimental Study of Dividing Open-Channel Flows", ASCE Journal of Hydraulic Engineering, Vol. 133, No. 10, pp. 1135-1144, 2007

[5] L. S. Nania, M. Gomez, J. Dolz, P. Comas, J. Pomares, "Experimental Study of Subcritical Dividing Flow in an Equal-Width, Four- Branch Junction", ASCE Journal of Hydraulic Engineering, Vol. 137, No. 10, pp. 1298-1305, 2011

[6] R. Ghobadian, "Analysis of Tailwater Surface Level on Secondary Flow Profile at Rectangular Open-Channel Junction by 3-D CFD Model", $4^{\text {th }}$ National Congress of Civil Eng., Tehran University, Tehran, Iran, 2010

[7] S. Gohari, "Lab Comparison of Flow Pattern between Diversion and Cross Flow", 9 ${ }^{\text {th }}$ Civil Eng. National Congress, May 8-10, Esfahan University of Technology, Esfahan, Iran, 2012 